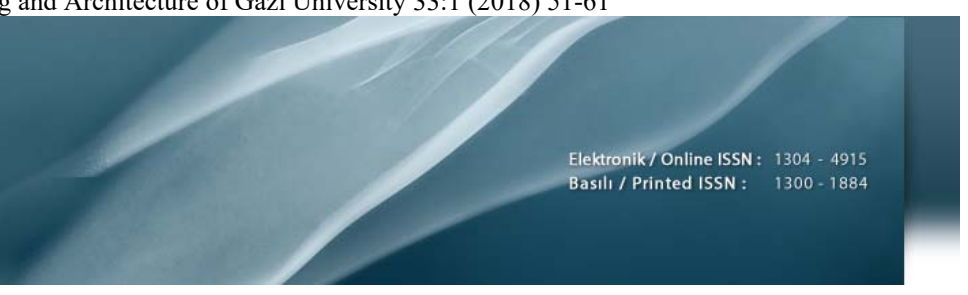

\title{
Pinyon-tipi takımla imal edilen standart olmayan dişlilerin bilgisayar simülasyonu
}

\author{
Mahmut Cüneyt Fetvac1*(i)
}

İstanbul Üniversitesi, Mühendislik Fakültesi, Makina Mühendisliği Bölümü, Avcılar, İstanbul, 34320, Türkiye

\section{Ö N E Ç I K A N L A R}

- İç ve dış dişlerin imalat simülasyonu

- Yan boşluksuz çalışan profil kaydırmalı dişliler

- Örnek uygulamalar ile doğrulama

Makale Bilgileri

Geliş: 10.03.2016

Kabul: 30.08 .2017

DOI:

10.17341/gazimmfd.406779

Anahtar Kelimeler:

Profil kaydırma,

evolvent dişliler,

yan boşluksuz çalışma,

pinyon takımlar

\section{ÖZET}

Bu çalışmada pinyon-tipi takımla imal edilen düz dişlilerin profillerinin bilgisayarda oluşturulması ele alınmıştır. Dişli teorisinden hareketle takımların ve imal edilen evolvent profilli iç ve dıș dişlilerin matematik modelleri verilmiştir. Yan boşluksuz çalışan profil kaydırılmış dişliler göz önüne alınmıştır. İmal eden ve imal edilen yüzeylerin bilgisayar grafikleri elde etmek için programlar geliștirilmiștir. Böylelikle çeşitli tasarım parametrelerinin çark diş profili üzerindeki etkiler imalattan önce incelenebilir.

\section{Computer simulation of nonstandard gears manufactured by pinion-type cutters}

\section{H I G H L I G H T S}

- Generation simulation of internal and external gears

- Corrected gears with zero backlash meshing

- Validation with illustrative examples

Article Info

Received: 10.03 .2016

Accepted: 30.08 .2017

DOI:

10.17341/gazimmfd.406779

Keywords:

Profile shift,

involute gears,

zero backlash meshing,

pinion cutters

\section{ABSTRACT}

This paper studies the computerised tooth profile generation of spur gears cut with pinion-type cutters. Based on the theory of gearing the mathematical models of generating cutters and generated external and internal gears with involute teeth are given. Generation of corrected gear sets meshing without any backlash are considered. Computer simulation programs are developed to obtain graphs of generating tools and generated teeth surfaces. The effect of tool parameters on generated gear can be investigated before manufacturing. 


\section{GÍRIŞ̧ (INTRODUCTION)}

Evolvent profilli düz ve helisel dişli çarklar paralel miller arasında güç ve hareket iletiminde yaygın olarak kullanılan makine elemanlarıdır. $\mathrm{Bu}$ dişlilerin seri imalatında yuvarlanma metodunu esas alan takımlar kullanılmaktadır. Yuvarlanma metodunda takım ve imal edilen dişli senkronize hareket eder ve eş çalışan dişli çifti simüle edilerek diş açma gerçekleştirilir. Burada döndüren dişliye döndürülen dişliyi şekillendirecek talaş kaldırıcı özellikler verilmiştir. Böylelikle sonsuz vida mekanizmasını simüle eden azdırma, kremayer-çark mekanizmasını simüle eden Maag ve pinyon-çark mekanizmasını simüle eden Fellow takım tezgahları geliştirilmiştir [1]. Kremayer takım ve azdırma sadece dış dişlileri imal ederken Fellow takım aynı zamanda iç dişlileri de imal etmektedir. Ayrıca uygun düzenlemelerle eliptik dişliler ve beveloid dişliler imal edilebilmektedir. Evolvent profilli bir dişli çark evolvent yanak, diş tabanı ve yanak ile tabanı birbirine bağlayan kök bölgelerinden oluşmaktadır. $\mathrm{Bu}$ bölgeler kesici takımın karşılık gelen yüzeyleri tarafından şekillendirilir. Dişli çarkın tabanı ve diş kökü kesici takımın uç geometrisine bağlı olarak imal edilir. Takımların uçları, köşelerinden yuvarlatılmış, tam yuvarlak ve sivri olabilir. Fellow takım (pinyon-tipi takım) görünüş itibariyle dişli çarka benzer fakat baş yüksekliği arttırılmış ve yüzeylerine kesici özellikler verilmiştir. Pinyon-tipi takımla dişli taslağın eş çalışması iki evolvent dişlinin baş boşluksuz ve yan boşluksuz eş çalışması ile benzerdir [2].

Diş profilinin matematik modellenmesi ve programlanarak bilgisayar ortamına aktarılması çeşitli dizayn parametrelerinin imal edilen dişlideki etkisini önceden inceleme firsatını verir. Ayrıca dişlilerin çeşitli çalışma koşullarında işletmedeki davranışını belirlenebilir [3]. Böylelikle tasarım aşamasında gerekli düzeltmeler yapılabilir. Literatürde çeşitli tipten dişlileri ve imal eden takımları modelleyen çok sayıda çalışma mevcuttur. Birçok çalışma Litvin tarafından geliştirilmiş Vektör Metodunu esas almaktadır [4]. Bu metotta imal eden takım yüzeyinin vektör ifadesinden hareketle koordinat dönüşüm, diferansiyel geometri ve dişli ana kanununu kullanarak dişli çark yüzeyleri elde edilir. Kesici takım geometrisi uygun bir kesitte vektör formda ifade edilmekte, helis, koniklik (beveloid), içbükeylik gibi özellikler uygun dönüşüm matrisleri ile gerçekleştirilmektedir. Asimetrik profil, uç düzeltme, taşlama payı ve benzeri fonksiyonel ve imalat esasli modifikasyonlar matematik modellere ilave edilebilmektedir. Gerek kremayer-tipi takımlar ve gerekse pinyon-tipi takımlar ile matematik modelleme ve analizinin ele alındığı çok sayıda çalışma sunulmuştur. Pinyon-tipi takım ile iç ve dış dişlileri modelleyen bazı çalışmalar aşağıda özetlenebilir. Chang ve Tsay [5], evolvent düz dişli pinyon takımın tüm imal edici yüzeylerinin vektör ifadesini sunmuşlar ve eliptik dişli geometrisi elde etmişlerdir. Tsay vd. [6], taşlama paylı düz dişli pinyon takımla standart yerleştirmeli ve profil kaydırmalı imalatın matematik modelini sunmuştur. Fetvacı [7], takım uç geometrisinin imal edilen dişli üzerindeki etkilerini incelemiş ve asimetrik dişli pinyon-tipi takımlarda mümkün olan uç geometrilerini belirtmiştir. Fetvac1 [8], Chang ve Tsay'in modelini, evolvent helisel dişli çarkların yuvarlak uçlu pinyon-tipi takımla imalatına uyarlamıştır. Ayrıca çalışmada imal edilen iç ve dış dişli çarkların diş başı yarıçaplarını otomatik belirleyen bir analitik yöntem önerilmiştir [8]. Liu vd. [9], düz beveloid dişlilerin pinyon-tipi takımla imalatının matematik modelini sunmuştur. Konik işlemeyi sağlamak üzere konvansiyel olarak takım ve taslak mil eksenleri kesişmektedir. Chen vd. [10], iç ve diş düz beveloid dişlilerin pinyon-tipi takımla imalatında yeni bir metot geliştirmiştir. $\mathrm{Bu}$ metotta takım ve taslak milleri paraleldir ve takıma konik işlemeyi sağlayacak yatay ve düşey eksende hareket serbestisi verilmiştir. Nemcek [11], yuvarlatılmış uçlu pinyon-tipi takım için maksimum evolvent noktası ile baş dairesi arasındaki radyal mesafe ile yuvarlatma yarıçapı arasındaki bağıntıyı çeşitli durumlar için incelemiştir. Zhou ve Song [12], iç dişli pompalarda debi karakteristiğini iyileştirmek ve dişli elemanların ömrünü artırmak için eşlenik evolvent profil kullanmışlardır. Ardışık dönüşümün kullanıldığı bu yaklaşımda evolvent yanaklara ilave olarak pinyonun kökü ile eşlenik formda iç dişli yuvarlatılmış baş ucu da devreye girmektedir. Ancak iç dişliyi belirleyen pinyon kesici sanaldır ve imalat tel erozyon tezgahında gerçekleşmektedir. Girișim ve alttan kesme dişli çark tekniğinde önlenmesi gereken önemli bir husustur. Gerek kremayer-tipi takımla imalatta ve gerekse pinyon-tipi takımla imalatta tasarım parametrelerine bağlı olan bir sınır diş sayısı söz konusudur. Pinyon takımla dış dişli çark imalatında takım kavrama açısı ve taksimat dairesinden ölçülen evolvent baş yüksekliğine bağlı olarak sınır diş sayısını tayin eden denklemleri Mabie ve Reinholtz sunmuştur [13]. İç dişli çarklarda ise gerek imalatta ve gerekse pinyon-çark eş çalışmasında görülen çeşitli girişim tipleri vardır. İç dişli çarkın diş başı yarıçapının temel dairesi yarıçapından daima büyük olması istenir. Girişimi önlemek için takım ve taslağın diş sayıları uygun seçilir. Litvin vd. [14], takım ve iç dişli taslak diş sayıları arasında montaj için sağlanması gereken bağıntıları sunmuştur. Pinyon-tipi takımlarda yuvarlatılmış uç formu diş sayısına da bağlı olduğundan imal edilen dişlilerde alt kesilmeyi önlemek için takım diş sayıları yüksek tutulmaktadır. Shavn [15], referans profildeki kök yuvarlatma formunu modifiye ederek takım diş sayısını azaltan bir yöntem geliştirmiştir. Profil kaydırma girişimi önlemek için kullanılan bir metottur. Ayrıca eksenler arası mesafeyi ayarlamak, dişli çiftinin kayma-kavrama durumunu iyileştirmek ve dişlerin mukavemetini artırmak amacıyla da uygulanmaktadır. İç dişli çark mekanizmalarında montaj için genellikle iç dişliye profil kaydırma yapılması gerekmektedir. Pinyontipi takımla imal edilen profil kaydırmalı dış dişlilerinin geometrik özellikleri Mabie and Reinholtz tarafindan verilmiştir [13]. Profil kaydırmada takım taslağa göre radyal yönde yaklaştırılır veya uzaklaştırılır. Böylelikle genişletilmiş (veya daraltılmış) bir eksenler arası mesafede eş çalışma söz konusudur. Profil kaydırmada imal edilen 
dişlinin diş başı ve diş dibi yarıçapları değişmektedir. Pinyona ve çarka verilen profil kaydırma miktarlarının toplamına göre mekanizma özellikleri değişmektedir. Bu toplam sıfırsa eksenler arası mesafe değişmez, sıfirdan farklı ise eksenler arası mesafe değişir ve mekanizma Vmekanizması olarak adlandırılır. Yan boşluklu VMekanizmalarında eksenler arası mesafedeki değişim profil kaydırma miktarlarının toplamı kadardır. Burada temas eden diş yanaklarında işletmede gürültü çalışmaya yol açan yanak boşluğu (backlash) söz konusudur. İstenmeyen yanak boşluğunu gidermek için genişletilmiş eksenler arası mesafe daraltılır. Böylece yan boşluksuz çalışan Vmekanizmaları elde edilir [1]. Yan boşluksuz Vmekanizmasında minimum baş boşluğunu (clearance) sağlamak üzere diş başı yarıçaplarının kısaltılması gerekebilir. Literatürde mevcut çalışmalarda profil kaydırma işlemi takım-taslak koordinat dönüşüm matrisinde veya takım yer vektöründe ifade edilmektedir. Kremayer-tipi takımı inceleyen birçok çalışmada detaylı bilgi verilmektedir. Pinyon-tipi takımı konu alan çalışmalarda ise genelde profil kaydırma ayrıntılı anlatılmamaktadır. Tsay vd. [6], dış dişlilerde takımın ve taslağın imalat taksimat yarıçapları yerine eş çalışma (yuvarlanma) yarıçapları yazarak profil kaydırmayı matematik modele uyarlamışlardır. Ancak profil kaydırmanın imal edilen geometrideki etkilerini incelememişlerdir. Çalışmadan hareketle, Fetvacı iç ve dış düz dişlilerin pinyon takımla imalatında profil kaydırmanın etkilerini incelemiştir [16]. Bununla birlikte gerek Tsay vd. nin ve gerekse Fetvacı'nın çalışmalarında profil kaydırma miktarı ile eksenler arası mesafedeki artışın eş tutulduğu yan boşluklu çalışma durumu göz önüne alınmıştır $[6,16]$. Ulaşılabilen açık literatürde yan boşluksuz profil kaydırmalı dişlilerin modelleme ve simülasyonu ile ilgili çalışmaların nadir olması yazarı bu konuda çalışmaya teşvik etmiştir.

$\mathrm{Bu}$ çalışmada pinyon takımla imal edilen iç ve dış düz dişlilerin matematik modellemesi ele alınmıştır. Profil kaydırma işlemi literatürde mevcut çalışmalardan farklı olarak yan boşluksuz eş çalışmayı sağlayacak şekilde uygulanmıştır. Çalışmanın ikinci bölümünde evolvent düz dişli pinyon-tipi takımın matematik modeli verilmiştir. Takip eden bölümde profil kaydırma işlemi de göz önüne alınarak imal edilen iç ve dış dişlilerin matematik modelleri verilmiştir. Dördüncü bölümde sınır diş sayıları, girişim ve profil kaydırma ele alınmıştır. Beşinci bölümde çeşitli dizayn parametrelerinin etkilerini gösteren bilgisayar uygulamaları verilmiştir. Bulguların değerlendirildiği ve sonuçların özetlendiği altıncı ve yedinci bölümlerle çalışma tamamlanmıştır.

\section{TAKIMIN MATEMATIK MODELI} (MATHEMATICAL MODEL OF THE CUTTER)

Takım yüzeyinin vektör modellenmesi bu yüzeyi oluşturan bölgelerin konum, teğet ve gerekirse eğrilik sürekliliğini sağlayacak şekilde yapılmaktadır. Şekil 1'de normal kesitte pinyon-tipi takım gösterilmektedir. Modellemede iki ayrı koordinat sistemi kullanılmaktadır. Referans koordinat sisteminde imal edici yüzeyi belirleyen denklemler kurulmakta ve takiben Kartezyen koordinatlara dönüşüm evolvent geometrisinden tayin edilen parametreyi içeren matris ile gerçekleşmektedir [4]. Düz dişli çarklarda diş profili diş genişliği boyunca değişmediğinden kolaylık açısından iki boyutlu modelleme göz önüne alınmıştır. Şekil 1'de görüldüğü üzere kesici takımın 1. bölgesi imal edilen dişlinin evolvent yanağını oluşturmaktadır. Takımın temel dairesi yarıçapı $r_{b}$ sembolü ile gösterilmektedir. Eğrisel parametre $\xi$ evolvent bölgedeki bir noktanın konumunu tayin etmekte ve $0 \leq \xi \leq \xi_{\mathrm{m}}$ aralığında değişmektedir. $\xi_{\mathrm{m}}$ maksimum evolvent açısıdır. Referans koordinat sisteminde bölgenin yer vektörü Eş. 1'de verilmektedir [5].

$\mathrm{R}_{\mathrm{r}}^{1}=\left\{\begin{array}{l}\mathrm{x}_{\mathrm{r}}^{1} \\ \mathrm{y}_{\mathrm{r}}^{1}\end{array}\right\}=\left\{\begin{array}{l}\mathrm{r}_{\mathrm{b}} \sin \xi-\mathrm{r}_{\mathrm{b}} \xi \cos \xi \\ \mathrm{r}_{\mathrm{b}} \cos \xi+\mathrm{r}_{\mathrm{b}} \xi \sin \xi\end{array}\right\}$

Takımın dairesel yay formunda 2 . bölgesi imal edilen dişlinin kökünü oluşturmaktadır. $\rho$ sembolü yuvarlatılmış uç köşesinin eğrilik yarıçapını gösterir. Şekil 1'de görüldüğü üzere evolvent bölge ile eğri sürekliğini sağlamak için yuvarlatılmış ucun eğrilik merkezi maksimum evolvent noktası A'dan temel dairesine indirilen teğet doğrusu PA üzerindeki E noktasında konumludur. Eğrisel parametre $\theta$ bölgedeki bir noktanın konumunu tayin etmekte ve $0 \leq \theta \leq \pi / 2-\tan ^{-1}\left(\xi_{\mathrm{m}}-\left(\rho / \mathrm{r}_{\mathrm{b}}\right)\right) \quad$ aralığında değişmektedir. Referans koordinat sisteminde bölgenin yer vektörü Eş. 2'de verilmektedir [5].

$\mathrm{R}_{\mathrm{r}}^{2}=$

$\left\{r_{b} \sin \xi_{m}-r_{b} \xi_{m} \cos \xi_{m}+\rho \cos \xi_{m}-\rho \cos \left(\theta+\xi_{m}\right)\right\}$

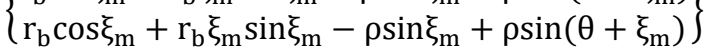

Takımın düz çizgi formda 3.bölgesi imal edilen dişlinin dairesel yay formda tabanını oluşturmaktadır. Eğrisel parametre $\eta$ takımın tavanındaki bir noktanın konumunu tayin etmekte ve $\xi_{\mathrm{m}}+\delta-\pi / 2 \leq \eta \leq \tan \alpha-\alpha+\pi / 2 \mathrm{~T}_{\mathrm{c}}$ aralığında değişmektedir. Referans koordinat sisteminde bölgenin yer vektörü Eş. 3'de verilmektedir [5].

$\mathrm{R}_{\mathrm{r}}^{3}=\left\{\begin{array}{l}\mathrm{x}_{\mathrm{r}}^{3} \\ \mathrm{y}_{\mathrm{r}}^{3}\end{array}\right\}=\left\{\begin{array}{l}\mathrm{r}_{\mathrm{B}} \sin \eta \\ \mathrm{r}_{\mathrm{B}} \cos \eta\end{array}\right\}$

$\mathrm{Bu}$ denklemde $\mathrm{r}_{\mathrm{B}}=\rho+\sqrt{ }\left(\mathrm{r}_{\mathrm{b}}{ }^{2}+\left(\mathrm{r}_{\mathrm{b}} \xi_{\mathrm{m}}-\rho\right)^{2}\right)$ takımın baş dairesi yarıçapıdır ve $\delta=\pi / 2-\tan ^{-1}\left(\xi_{\mathrm{m}}-\left(\rho / \mathrm{r}_{\mathrm{b}}\right)\right)$ dır. Referans koordinat sisteminde elde edilen denklemler uygun dönüşümle Kartezyen koordinatlarda ifade edilebilir. Evolvent geometrisinden hareketle döndürme açısı $\psi$, takım diş sayısı $T_{c}$ ve normal kesitteki kavrama açısı $\alpha$ olmak üzere $\psi=\tan \alpha-\alpha+\pi / 2 \mathrm{~T}_{\mathrm{c}}$ ifadesiyle hesaplanır. Böylelikle Eş. 4 kullanılarak takım geometrisi Kartezyen koordinatlarda elde edilir [5].

$\mathrm{R}_{\mathrm{c}}^{\mathrm{i}}=\left\{\begin{array}{l}\mathrm{x}_{\mathrm{c}}^{\mathrm{i}} \\ \mathrm{y}_{\mathrm{c}}^{\mathrm{i}}\end{array}\right\}=\left[\begin{array}{cc}\sin \psi & \cos \psi \\ -\cos \psi & \sin \psi\end{array}\right]\left\{\begin{array}{l}\mathrm{x}_{\mathrm{r}}^{\mathrm{i}} \\ \mathrm{y}_{\mathrm{r}}^{\mathrm{i}}\end{array}\right\}$ 


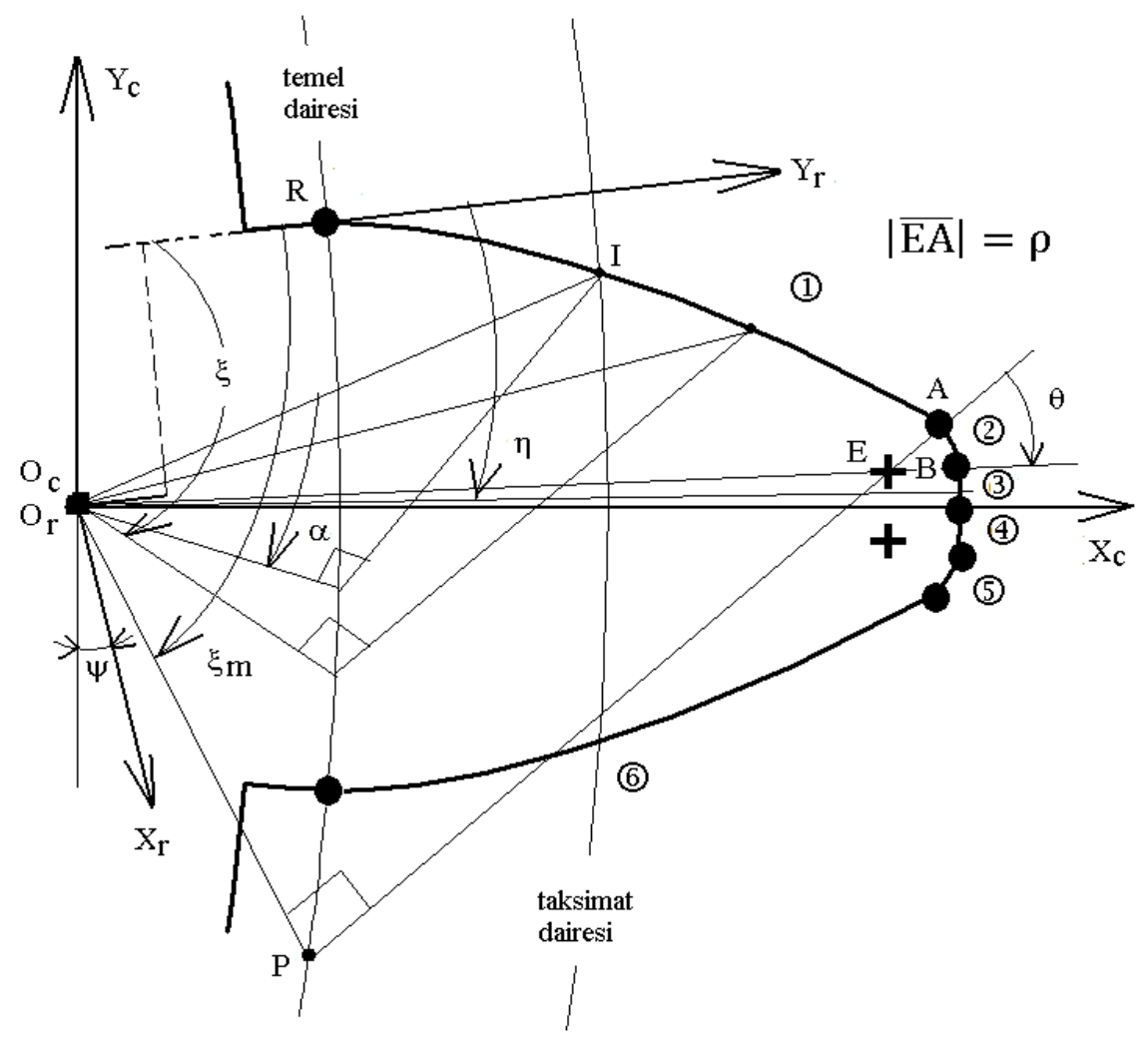

Şekil 1. Pinyon-tipi takımın normal kesiti (Normal section of the pinion-type cutter)

Takımın sağ tarafında karşı gelen bölgelerin koordinatları uygun işaretlemelerle yazılabilir. Takımın evolvent formda 1. ve 6 . bölgeleri Kartezyen koordinatlarda Eş. 5'de ifade edilebilir [5].

$R_{c}^{1,6}=\left\{\begin{array}{l}x_{c}^{1,6} \\ y_{c}^{1,6}\end{array}\right\}=\left\{\begin{array}{c}r_{b} \cos (\xi-\psi)+r_{b} \xi \sin (\xi-\psi) \\ \mp r_{b} \sin (\xi-\psi) \pm r_{b} \xi \cos (\xi-\psi)\end{array}\right\}$

Bu denklemde üst işaret takımın 1. bölgesini ve alt işaret 6 . bölgesini gösterir.

Diferansiyel geometriden, $\mathrm{S}_{\mathrm{c}}$ koordinat sisteminde ifade edilen takım yüzeylerinin normal vektörleri Eş. 6' da, birim normal vektörleri ise Eş. 7'de hesaplanır [4].

$\mathrm{N}_{\mathrm{c}}^{\mathrm{i}}=\frac{\partial \mathrm{R}_{\mathrm{c}}^{\mathrm{i}}}{\partial \mathrm{l}_{\mathrm{j}}} \times \mathrm{k}$

$\mathrm{n}_{\mathrm{c}}^{\mathrm{i}}=\frac{\frac{\partial \mathrm{R}_{\mathrm{c}}^{\mathrm{i}} \times \mathrm{k}}{\partial \mathrm{l}_{\mathrm{j}}}}{\left|\frac{\partial \mathrm{R}_{\mathrm{c}}^{\mathrm{i}} \times \mathrm{k}}{\partial \mathrm{l}_{\mathrm{j}}}\right|}$

Burada $l_{j}$ parametresi sırasıyla takımın eğrisel parametreleri $\xi, \theta$ ve $\eta$ yi gösterir.

Takımın evolvent formda 1 ve 6 . bölgelerinin normal vektörleri Eş. 5 ve Eş. 6'dan hesaplanabilir. Eş. 8'de üst işaret birinci (sol) alt işaret altıncı (sağ) bölgeleri ifade eder.
$\mathrm{N}_{\mathrm{c}}^{1,6}=\frac{\partial \mathrm{R}_{\mathrm{c}}^{1,6}}{\partial \mathrm{l}_{\mathrm{j}}} \times \mathrm{k}=\mathrm{r}_{\mathrm{b}} \xi\left\{\begin{array}{c}\mp \sin (\xi-\psi) \\ -\cos (\xi-\psi) \\ 0\end{array}\right\}$

\section{3. İMAL EDİLEN DİŞLİNIN MATEMATIKK MODELI (MATHEMATICAL MODEL OF THE GENERATED GEAR)}

\subsection{Dış Dişli Çarklar (External Gears)}

Şekil 2'de takım ile imal edilen dış dişli arasındaki kinematik bağ gösterilmektedir. Profil kaydırmada göz önüne alınarak koordinat sistemleri konumlandırılmıştır. $\mathrm{S}_{\mathrm{f}}\left(\mathrm{X}_{\mathrm{f}}, \mathrm{Y}_{\mathrm{f}}\right)$ sabit olan referans koordinat sistemidir ve orijini kaydırılmamış takımın ağırlık merkezi olan $(0,0)$ noktasında konumludur. Pozitif profil kaydırmada takım taslaktan uzaklaştığından, pinyon takımın hareketli koordinat sistemi $\mathrm{S}_{\mathrm{c}}\left(\mathrm{X}_{\mathrm{c}}, \mathrm{Y}_{\mathrm{c}}\right)$ şekilde gösterildiği gibidir. $\mathrm{S}_{\mathrm{g}}\left(\mathrm{X}_{\mathrm{g}}, \mathrm{Y}_{\mathrm{g}}\right)$ imal edilen çark dişlisinin hareketli koordinat sistemidir ve orijini çarkın ağırlık merkezindedir. Yuvarlanma prosesinde pinyon takım $\phi_{\mathrm{c}}$ açısı kadar dönerken imal edilen çark ise $\phi_{\mathrm{g}}$ açısı kadar dönmektedir. $\mathrm{S}_{\mathrm{c}}\left(\mathrm{X}_{\mathrm{c}}, \mathrm{Y}_{\mathrm{c}}\right)$ ve $\mathrm{S}_{\mathrm{g}}\left(\mathrm{X}_{\mathrm{g}}, \mathrm{Y}_{\mathrm{g}}\right)$ koordinatları arasındaki dönüşüm matrisi Eş. 9'da verilmiştir.

$\left[\mathrm{M}_{\mathrm{gc}}\right]=$

$\left[\begin{array}{ccc}\cos \left(\phi_{\mathrm{c}}+\phi_{\mathrm{g}}\right) & \sin \left(\phi_{\mathrm{c}}+\phi_{\mathrm{g}}\right) & -\left(\mathrm{r}_{\mathrm{c}}^{*}+\mathrm{r}_{\mathrm{g}}^{*}\right) \cos \phi_{\mathrm{g}} \\ -\sin \left(\phi_{\mathrm{c}}+\phi_{\mathrm{g}}\right) & \cos \left(\phi_{\mathrm{c}}+\phi_{\mathrm{g}}\right) & \left(\mathrm{r}_{\mathrm{c}}^{*}+\mathrm{r}_{\mathrm{g}}^{*}\right) \sin \phi_{\mathrm{g}} \\ 0 & 0 & 1\end{array}\right]$ 


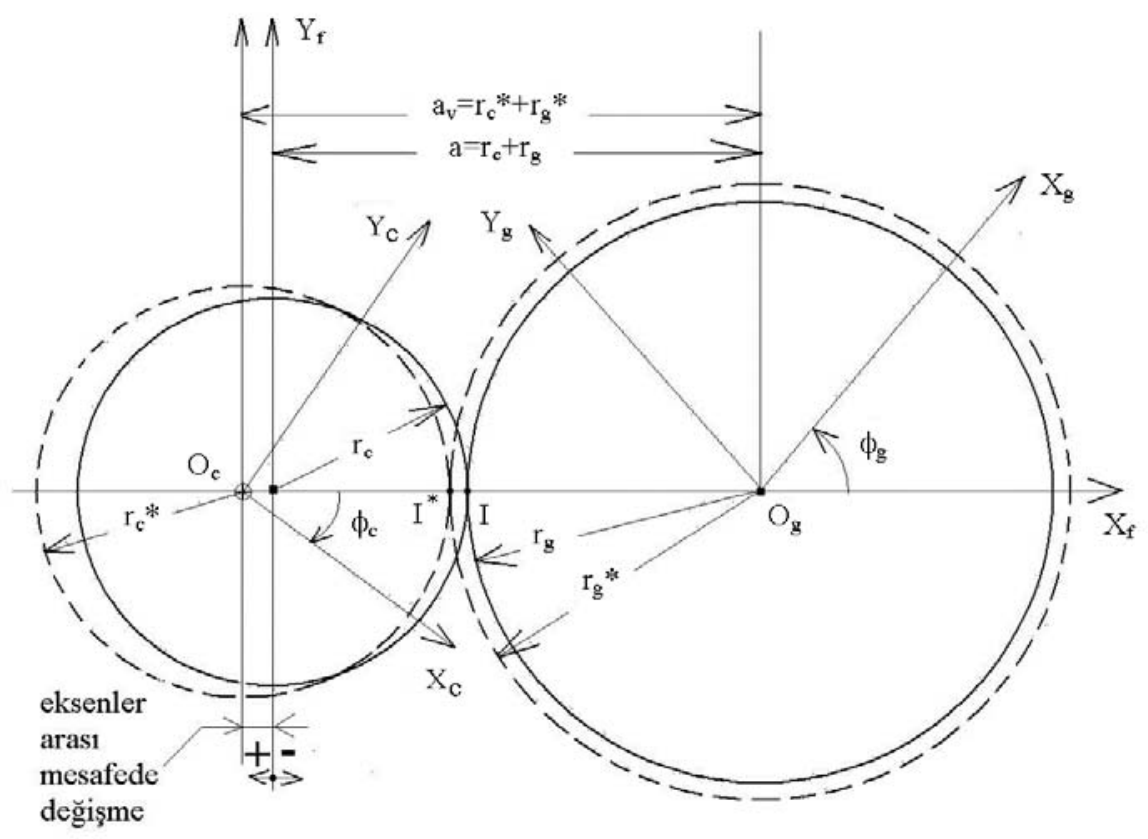

Şekil 2. Pinyon takım ve dış dişli çark arasındaki koordinat bağı (Coordinate relationship between cutter and external gear blank)

Takım diş sayısı $T_{c}$ ve taslak diş sayısı olmak $T_{g}$ üzere yuvarlanma parametreleri arasında $\phi_{\mathrm{g}}=\left(\mathrm{T}_{\mathrm{c}} / \mathrm{T}_{\mathrm{g}}\right) / \phi_{\mathrm{c}}$ iliş̧kisi vardır. Şekilde eş çalışma daireleri kesikli çizgi ile gösterilmiştir. Yarıçaplar sırasıyla $r_{c}{ }^{*}$ ve $r_{g}{ }^{*}$ sembolleriyle gösterilmektedir. Ani dönme merkezi I* noktasıdır. Profil kaydırma yoksa sürekli çizgi ile gösterilen taksimat daireleri ve yarıçapları göz önüne alınır. $\mathrm{Bu}$ durumda ani dönme merkezi I noktasıdır. Pinyon takımın geometrik yeri çarkın koordinat sisteminde (9) numaralı denklemde verilen dönüşüm matrisi kullanılarak Eş. 10 ile ifade edilir [4].

$\mathrm{R}_{\mathrm{g}}^{\mathrm{i}}=\left[\mathrm{M}_{\mathrm{gc}}\right] \mathrm{R}_{\mathrm{c}}^{\mathrm{i}}$

Dişli Ana Kanunu gereğince takım ve taslak yüzeylerinin müşterek normali daima izafi ani dönme merkezinden geçmelidir. $\mathrm{Bu}$ kanunun matematik ifadesi eş çalışma denklemi Eş. 11'de verilmiştir [4].

$\frac{X_{c}-x_{c}^{i}}{n_{c x}^{i}}=\frac{Y_{c}-y_{c}^{i}}{n_{c y}^{i}}$

Ani dönme merkezi I* noktasının koordinatları $\mathrm{X}_{\mathrm{c}}=\mathrm{r}_{\mathrm{c}}{ }^{*} \cos \phi_{\mathrm{c}}$ ve $Y_{c}=r_{c}{ }^{*} \sin \phi_{c}$ dir. Takım yüzeyinin koordinatları $x_{c}^{i}$ ve $y_{c}^{i}$ dir. $S_{c}$ koordinat sisteminde birim normal vektörün bileşenleri $\mathrm{n}_{\text {cx }}^{\mathrm{i}}$ ve $\mathrm{n}_{\text {cy }}^{\mathrm{i}}$ sembolleriyle gösterilmektedir. Sonuç olarak imal edilen dişlinin matematik modeli Eş. 10 ve Eş. 11 ifadelerinin eşzamanlı çözümü ile elde edilir.

\section{2. İ̧ Dişli Çarklar (Internal Gears)}

Şekil 3'de pinyon takımla iç dişli arasındaki kinematik bağ gösterilmektedir. Koordinat sistemleri önceki mekanizmaya benzer şekilde alınmış ve konumlandırılmıştır. Burada fark takım ve taslağın aynı yönde dönmesidir. Pozitif profil kaydırmada takım taslağa yaklaşmaktadır. Önceki modelde olduğu gibi kesikli çizgilerle gösterilen daireler profil kaydırma durumundaki eş çalışma taksimat (yuvarlanma) daireleridir ve eksenlere arası mesafedeki değişme $\mathrm{O}_{\mathrm{f}} \mathrm{O}_{\mathrm{c}}=\mathrm{a}_{\mathrm{v}}{ }^{-}$ a olarak hesaplanır. Koordinat dönüşüm matrisi Eş. 12'de verilmiştir.

$$
\begin{aligned}
& {\left[\mathrm{M}_{\mathrm{gc}}\right]=} \\
& {\left[\begin{array}{ccc}
\cos \left(\phi_{\mathrm{g}}-\phi_{\mathrm{c}}\right) & -\sin \left(\phi_{\mathrm{g}}-\phi_{\mathrm{c}}\right) & \left(\mathrm{r}_{\mathrm{g}}^{*}-\mathrm{r}_{\mathrm{c}}^{*}\right) \cos \phi_{\mathrm{g}} \\
\sin \left(\phi_{\mathrm{g}}-\phi_{\mathrm{c}}\right) & \cos \left(\phi_{\mathrm{g}}-\phi_{\mathrm{c}}\right) & \left(\mathrm{r}_{\mathrm{g}}^{*}-\mathrm{r}_{\mathrm{c}}^{*}\right) \sin \phi_{\mathrm{g}} \\
0 & 0 & 1
\end{array}\right]}
\end{aligned}
$$

Takımın taslak koordinat sisteminde ifade edilen geometrik yeri Eş. 12, Eş. 10'da yerine konularak elde edilir ve Eş. 11 ile eş zamanlı çözülerek iç dişli çarkın matematik modeli elde edilir.

\section{SINIR DİŞ SAYILARI VE PROFIL KAYDIRMA (MINIMUM NUMBERS OF TEETH AND PROFILE SHIFT)}

Eş çalışan dış-dış veya iç-dış dişli çark mekanizmalarında diş sayılarının seçilmesinde bazı sınırlamalar bulunmaktadır. Bu sınırlamalara dikkat edilmediği takdirde girişim söz konusudur. Benzer şekilde kesici takım ile imal edilen dişli sayıları girişim nedeniyle keyfi olarak seçilememektedir. Girişim tehlikesini önlemek üzere sıklıkla kullanılan yöntem profil kaydırmalı imalattır.

\subsection{Dıș Dişli Çarklarda Sınır Diș Sayısı (Minimum Numbers of Teeth for External Gears)}

Eş çalışan dış dişli çark mekanizmasında girişim olmaması için diş sayıları arasındaki bağıntı aşağıdadır. Burada diş başı yüksekliği standart değeri $\mathrm{f}=1,00$ alınır [13]. 


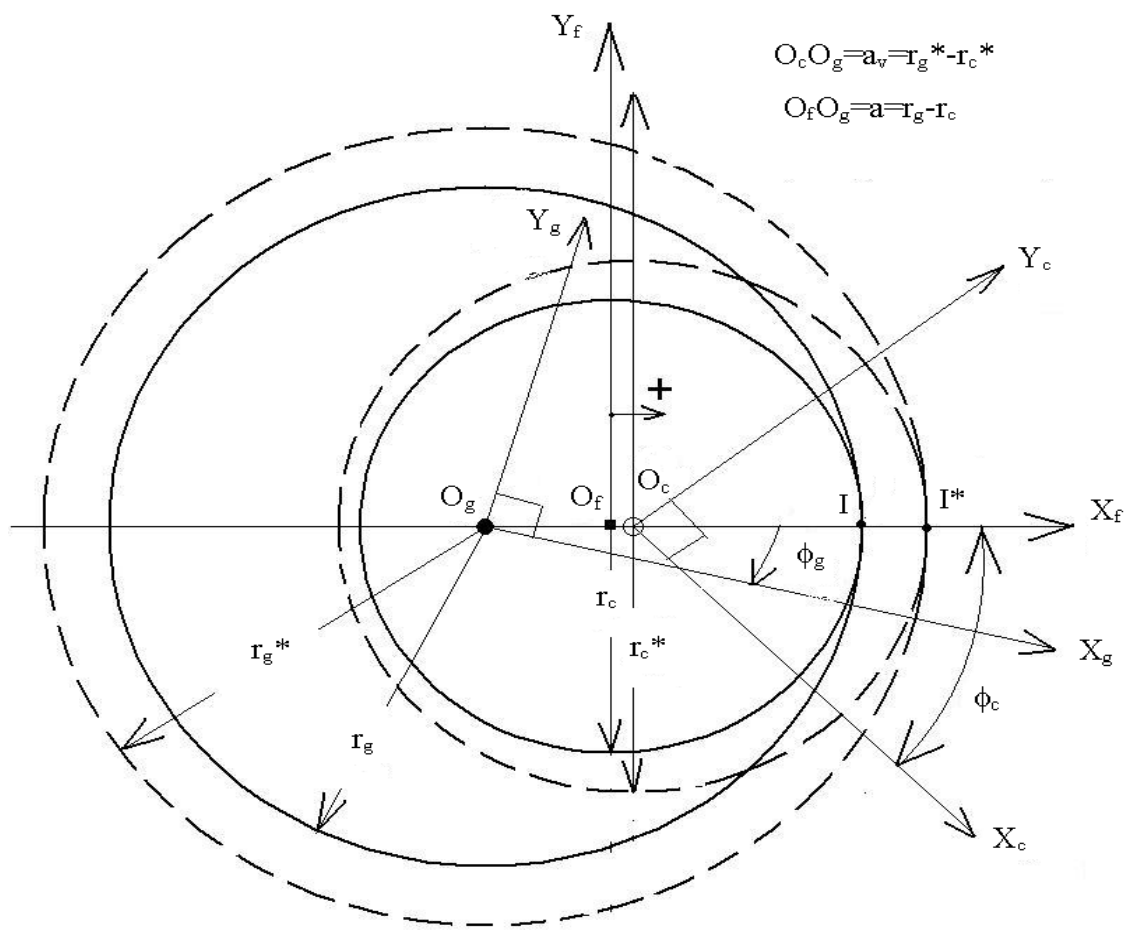

Şekil 3. Pinyon takım ve iç dişli çark arasındaki koordinat bağ (Coordinate relationship between cutter and internal gear blank)

$\mathrm{N}_{1}^{2} \sin ^{2} \alpha+2 \mathrm{~N}_{1} \mathrm{~N}_{2} \sin ^{2} \alpha-\frac{4 \mathrm{f}}{\sin ^{2} \alpha}\left(\mathrm{N}_{2}+\mathrm{f}\right)=0$

Aynı ifade Eş. 14 ile pinyon takımla dış dişli imalatına uyarlanabilir. Böylece takım diş sayısı verildiğinde alttan kesilmesiz çark diş sayısı bulunur. Burada sivri uçlu takım için taksimat dairesi üzerinden ölçülen diş yüksekliği $\mathrm{f}=1,25$ alınır [13].

$T_{g \text { min }}=-T_{c}+\sqrt{T_{c}^{2}+\frac{4}{\sin ^{2} \alpha}\left(\mathrm{fT}_{c}+\mathrm{f}^{2}\right)}$

Köşelerinden yuvarlatılmış takım durumunda taksimat dairesi ile maksimum evolvent dairesi arasındaki radyal mesafenin hesaplanması gerekir. Şekil 1'den hareketle Eş. 15-17 ifadeleri yazılabilir.

$\overline{\mathrm{PE}}^{2}+\overline{\mathrm{OP}}^{2}=\overline{\mathrm{OE}}^{2}=(\overline{\mathrm{OB}}-\overline{\mathrm{BE}})^{2}$

$\overline{\mathrm{PA}}=\overline{\mathrm{PE}}+\overline{\mathrm{EA}}$

$\overline{\mathrm{PA}}^{2}+\overline{\mathrm{OP}}^{2}=\overline{\mathrm{OA}}^{2}=\mathrm{R}_{\mathrm{A}}^{2}$

Maksimum evolvent yarıçapı takım dişbaşı çapı, uç yuvarlatma yarıçapı ve temel dairesi yarıçapına bağlı olarak Eş.18 ile hesaplanabilir.

$R_{A}=\sqrt{\left(R_{B}-\rho\right)^{2}+\rho^{2}+2 \rho \sqrt{\left(R_{B}-\rho\right)^{2}-r_{b}^{2}}}$

Sonuç olarak köşelerinden yuvarlatılmış uçlu takımda radyal yükseklik Eş. 19 ile hesaplanır.
$f=\left(R_{A}-r_{c}\right) / m$

Alternatif olarak maksimum evolvent yarıçapı maksimum evolvent açısına bağlı olarak Eş. 21 ile hesaplanabilir.

$\overline{\mathrm{PA}}=\overline{\mathrm{PE}}+\overline{\mathrm{EA}}=\widehat{\mathrm{PR}}=\mathrm{r}_{\mathrm{b}} \xi_{\mathrm{m}}$

$\xi_{\mathrm{m}}=\frac{\sqrt{\left(\mathrm{R}_{\mathrm{B}}-\rho\right)^{2}-\mathrm{r}_{\mathrm{b}}^{2}}+\rho}{\mathrm{r}_{\mathrm{b}}}$

Eş.18 düzenlenerek maksimum evolvent yarıçapı Eş. 22'de verilen denklemle de elde edilebilir.

$\mathrm{R}_{\mathrm{A}}=\sqrt{\mathrm{r}_{\mathrm{b}}^{2}+\mathrm{r}_{\mathrm{b}}^{2} \xi_{\mathrm{m}}^{2}}$

\subsection{Dış Dişli Çarklarda Profil Kaydırma (Profil Shifting for External Gears)}

Profil kaydırma faktörü verildiğinde yan boşluksuz durumda eş çalışma kavrama açısı Eş. 23'de verilen denklem ile bulunur.

$\mathrm{x}_{1}+\mathrm{x}_{2}=\frac{\mathrm{ev} \alpha_{\mathrm{v}}-\mathrm{ev} \alpha}{2 \tan \alpha}\left(\mathrm{N}_{1}+\mathrm{N}_{2}\right)$

Pinyon takımla yan boşluksuz profil kaydırmalı diş açmada Eş. 24'de verilen denklem kullanılır.

$\mathrm{x}_{\mathrm{c}}+\mathrm{x}_{\mathrm{g}}=\frac{\mathrm{ev} \alpha_{\mathrm{v}}-\mathrm{ev} \alpha}{2 \tan \alpha}\left(\mathrm{T}_{\mathrm{c}}+\mathrm{T}_{\mathrm{g}}\right)$ 
Takımın kendi profil kaydırma faktörü $\mathrm{x}_{\mathrm{c}}$ bu çalışmada göz önüne alınmamıştır. Dolayısıyla $\mathrm{x}_{\mathrm{c}}=\mathrm{x}_{1}$ pinyona verilen değere eşittir. Burada $\alpha_{\mathrm{v}}$ kavrama açısı iyi bir yaklaşımla $\lambda=\tan \alpha_{v}-\alpha_{v}$ olmak üzere Eş. 25 ile hesaplanır [4].

$\alpha_{\mathrm{v}}=(3 \lambda)^{1 / 3}-\frac{2}{5} \lambda+\frac{9}{175} 3^{2 / 3} \lambda^{5 / 3}-\frac{2}{175} 3^{1 / 3} \lambda^{7 / 3}+\cdots$

Böylece eş çalışma eksenler arası mesafe eş. 26 ile hesaplanir.

$\mathrm{a}_{\mathrm{v}}=\frac{\mathrm{a} \cdot \cos \alpha}{\cos \alpha_{\mathrm{v}}}$

Profil kaydırma miktarı ile diş üstü çapları değiştiğinden eş çalışan dişlilerde standart baş boşluğunu sağlamak üzere diş üstü çaplarını kısaltmak gerekebilir. Taslak çapları diş açma işleminden önce $r_{a}{ }^{\prime}=a_{v}+m-m_{1}-r_{1}$ değerini sağlayacak şekilde tornalanır. Kısaltmaya gerek yoksa, diş üstü çapı $\mathrm{r}_{\mathrm{a}}=\mathrm{r}_{2}+\mathrm{m}+\mathrm{mx}_{2}$ değerine göre tornalanır. Takım standart değerden daha büyük bir diş derinliği sağlamaktadır. Diş dibi yarıçapının teorik tam değeri genişletilmiş eksenler arası mesafe ve takım diş başı yarıçapı kullanılarak $\mathrm{r}_{\text {f̧̧ark }}^{\prime}=\mathrm{a}_{\mathrm{v}}-\mathrm{r}_{\mathrm{c}}-1,25 \mathrm{~m}$ ifadesi ile hesaplanır [2].

\section{3. İç Dişli Çarklarda Sınır Diş Sayısı (Minimum Numbers of Teeth for Internal Gears)}

Diş başı çap1 temel dairesinin altında ise evolvent girişim söz konusudur. Bu girişimi önlemek için bir yöntem taslak diş başı çapının diş açmadan önce Eş. 27'deki ifade ile hesaplanan değere torna edilmesidir [1]. Böylece iç dişli çarkın baş yüksekliği standart değerden küçük olmaktadır.

$r_{a}^{\prime}=\sqrt{\left(r_{g}-m\right)^{2}+(m / \tan \alpha)^{2}}$

$\mathrm{Bu}$ girişimin olmaması için standart baş yüksekliği ile imal edilmesi gereken minimum diş sayısı ise Eş. 28'deki ifade ile hesaplanabilir.

$\mathrm{T}_{\mathrm{g} \min } \geq \frac{2}{1-\cos \alpha}$

Evolvent girişimi önlemek için diğer bir yöntem profil kaydırmadır.

\subsection{Iç Dişli Çarklarda Profil Kaydırma \\ (Profil Shifting for Internal Gears)}

İç dişli çark mekanizmalarında profil kaydırma faktörü verildiğinde yan boşluksuz durumda eş çalışma kavrama açısı Eş. 29'da verilen denklemle bulunur.

$\mathrm{x}_{2}-\mathrm{x}_{1}=\frac{\mathrm{ev} \alpha_{\mathrm{v}}-\mathrm{ev} \alpha}{2 \tan \alpha}\left(\mathrm{N}_{2}-\mathrm{N}_{1}\right)$

Pinyon takımla yan boşluksuz profil kaydırmalı diş açmada Eş. 30'da verilen denklem kullanılır.

$\mathrm{x}_{\mathrm{g}}-\mathrm{x}_{\mathrm{c}}=\frac{\mathrm{ev} \alpha_{\mathrm{v}}-\mathrm{ev} \alpha}{2 \tan \alpha}\left(\mathrm{T}_{\mathrm{g}}-\mathrm{T}_{\mathrm{c}}\right)$
25 ve 26 numaralı denklemler kullanılarak eş çalışma kavrama açısı ve eş çalışma eksenler arası mesafe hesaplanır. İmal edilen diş başı yarıçapı eğer profil kaydırma durumunda kısaltmaya gerek varsa önce $\mathrm{r}_{\mathrm{a}}{ }^{\prime}=\mathrm{r}_{1}+\mathrm{a}_{\mathrm{v}}-\mathrm{m}-\mathrm{mx}_{1}$ değerini sağlayacak şekilde torna edilir. Kisaltmaya gerek yoksa $r_{a}=r_{2}-m+m_{2}$ dir. Takım standart değerden daha büyük bir diş derinliği sağlamaktadır. Diş dibi yarıçapının teorik tam değeri genişletilmiş eksenler arası mesafe ve takım diş başı yarıçapı kullanılarak $\mathrm{r}_{\text {f̧̧ark }}^{\prime}=$ $\mathrm{a}_{\mathrm{v}}+\mathrm{r}_{\mathrm{c}}+1,25 \mathrm{~m}$ ifadesiyle hesaplanir [2].

\subsection{Yan Boșluklu Profil Kaydırma Kaydırma (Profil Shifting with Backlash)}

V-mekanizmalarında imalat taksimat daireleri ile yuvarlanma daireleri farklıdır. Mekanizmayı oluşturan dişlilere verilen profil kaydırma miktarlarının toplamı kadar eksenler arası mesafe değişmektedir. Ancak Şekil 4'de görüldüğü üzere dişler referans profiline farklı noktalarda temas etmektedir. Eş çalışan dişler arasında yan boşluk (backlash) olarak adlandıran bir boşluk oluşmaktadır. Bu boşluk gürültülü çalışmaya neden olmaktadır.

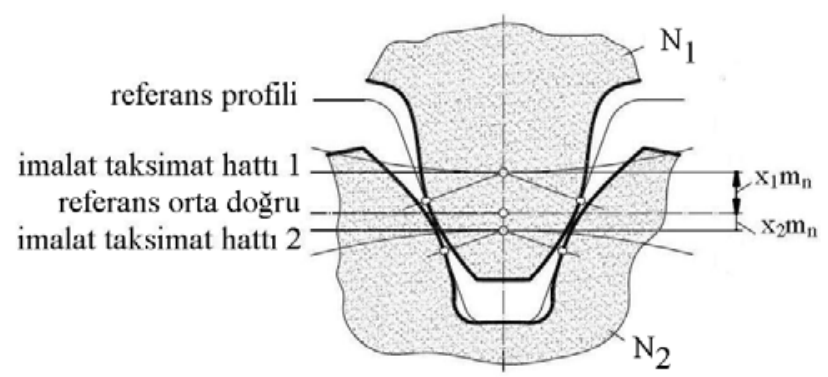

Şekil 4. Yan boşluklu kaydırılmış dişliler (Profile shifted gears with backlash) [2]

Genişletilmiş eksenler arası mesafe modül, diş sayıları ve profil kaydırma oranlarına göre Eş. 31'deki ifade ile hesaplanır.

$a_{v}=\frac{m}{2}\left(N_{1}+N_{2}\right)+m\left(x_{1}+x_{2}\right)$

İç dişli çark mekanizmalarında ise Eş. 32 kullanılarak hesaplama yapilır.

$\mathrm{a}_{\mathrm{v}}=\frac{\mathrm{m}}{2}\left(\mathrm{~N}_{2}-\mathrm{N}_{1}\right)-\mathrm{m}\left(\mathrm{x}_{1}-\mathrm{x}_{2}\right)$

\section{BILGISAYAR UYGULAMALARI (COMPUTER APPLICATIONS)}

Çeşitli tasarım parametrelerinin ve profil kaydırmanın imal edilen dişli çark geometrisini etkileri önceki bölümlerde verilen matematik modellerin uygun bir programla lisanı ile bilgisayar ortamına aktarılması ve sonuçların görselleştirilmesi ile incelenebilir. Şekil 5'de pinyon şeklinde takım ve imal ettiği dış düz dişli profili gösterilmektedir. Modül $\mathrm{m}=5 \mathrm{~mm}$, takım diş sayısı $\mathrm{T}_{\mathrm{c}}=20$, çark diş sayısı $\mathrm{T}_{\mathrm{g}}=75$, kavrama açısı $\alpha=20^{\circ}$, ve takım uç eğrilik yarıçapı $\rho=0,25 \times \mathrm{m}$ olarak alınmıştır. Çarka 
uygulanan profil kaydırma faktörü $\mathrm{x}_{2}=0,519$ dir. Standart eksenler arası mesafe $a=237,5 \mathrm{~mm}$, genişletilmiş eksenler aras1 mesafe $a=240 \mathrm{~mm}$ ve eş çalışma kavrama açısı $\alpha_{v}=21,58^{\circ}$ dir.

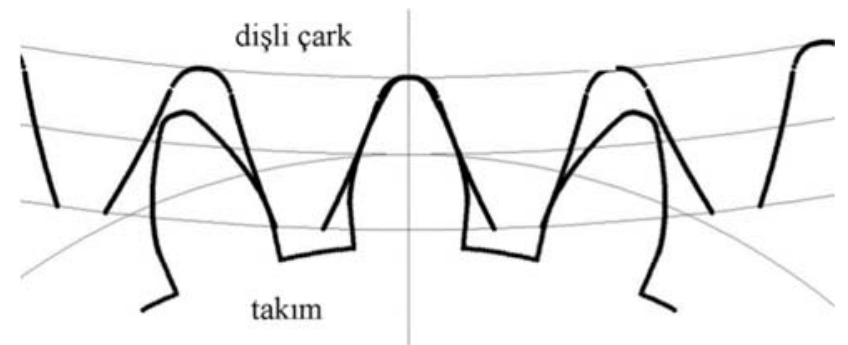

Şekil 5. Takım ve imal edilen dişli geometrisi (Cutter and manufactured gear teeth)

Şekil 6'da pinyon şeklinde takım ve imal ettiği dış düz dişli profili gösterilmektedir. Modül $\mathrm{m}=3 \mathrm{~mm}$, takım diş sayısı $T_{\mathrm{c}}=25$, çark diş sayısı $\mathrm{T}_{\mathrm{g}}=60$, kavrama açısı $\alpha=20^{\circ}$, ve takım uç eğrilik yarıçapı $\rho=0,25 \times$ m olarak alınmıştır. Çarka uygulanan profil kaydırma faktörü $\mathrm{x}_{2}=2,54$ dir. Burada imal edilen dişli çarkta sivri tepe oluşmuştur. Şekil 7'de gösterildiği üzere, sivri tepeyi önlemek ve çarkın 25 diş sayılı bir pinyonla çalışmasında minimum baş boşluğunu sağlamak üzere baş kısaltması yapılır. Standart eksenler aras1 mesafe $a=127,5 \mathrm{~mm}$, genişletilmiş eksenler arası mesafe $a_{v}=134,034 \mathrm{~mm}$ ve eş çalışma kavrama açısı $\alpha_{v}=26,634^{\circ}$ dir. Sivri tepenin olduğu diş baş1 yarıçapı $\mathrm{r}_{\mathrm{a}}=100,62 \mathrm{~mm}$, k1saltma miktarı $\mathrm{k}=-1,086 \mathrm{~mm}$, mekanizmada baş boşluğunu sağlayan diş başı yarıçapı $\mathrm{r}_{\mathrm{a}}=99,534 \mathrm{~mm}$ dir.

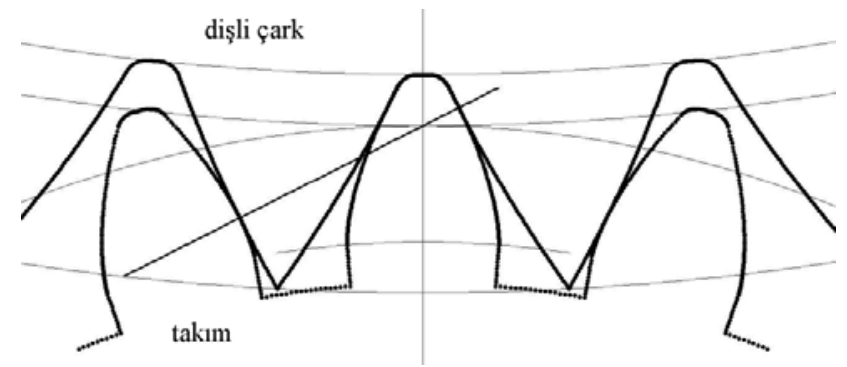

Şekil 6. Sivri tepeli dişli çark (Gear teeth with a zero topland)

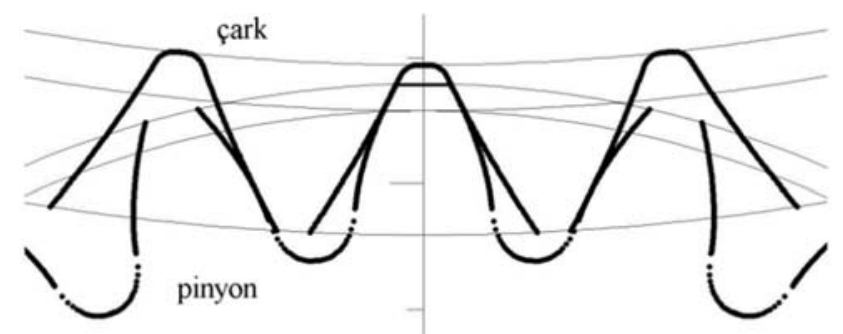

Şekil 7. Pinyon-çark mekanizması (Pinion-wheel mechanism)

Şekil 8'de pinyon-tip takım ve imal ettiği iç düz dişli profili gösterilmektedir. Modül $\mathrm{m}=3 \mathrm{~mm}$, takım diş sayısı $\mathrm{T}_{\mathrm{c}}=16$, çark diş sayısı $T_{\mathrm{g}}=24$, kavrama açısı $\alpha=20^{\circ}$ ve takım uç eğrilik yarıçapı $\rho=0,0 \mathrm{~mm}$ olarak alınmıştır. İmal edilen diş sayısı 34'ün altında olduğu için baş dairesi temel dairesinin altında oluşur. İlk çözüm olarak iç dişli baş yüksekliği standart değerin altında alınmıştır. Böylece aktif profilin tamamen evolvent olması sağlanmıştır. Ancak takım ve çark diş sayıları arasındaki fark 9'dan küçük olduğu için takım uç girişimi (trokoidal girişim) önlenememiştir [17]. Şekil 9'da gösterildiği üzere standart baş yüksekliği ve profil kaydırma uygulanarak bu iki girişim önlenmiştir. Çarka uygulanan profil kaydırma faktörü $\mathrm{x}_{2}=0,516$, standart eksenler arası mesafe $\mathrm{a}=12 \mathrm{~mm}$, genişletilmiş eksenler arası mesafe $a_{\mathrm{v}}=13,2 \mathrm{~mm}$ ve eş çalışma kavrama açısı $\alpha_{\mathrm{v}}=31,321^{\circ}$ dir. İç dişli çark mekanizması Şekil 10'da gösterilmiştir.

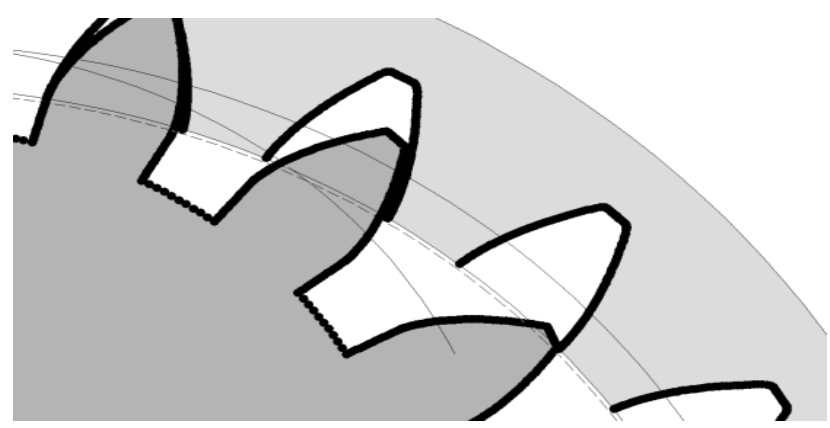

Şekil 8. Takım ve taslak diş ucu girişimi (Trochoidal interference of the cutter)

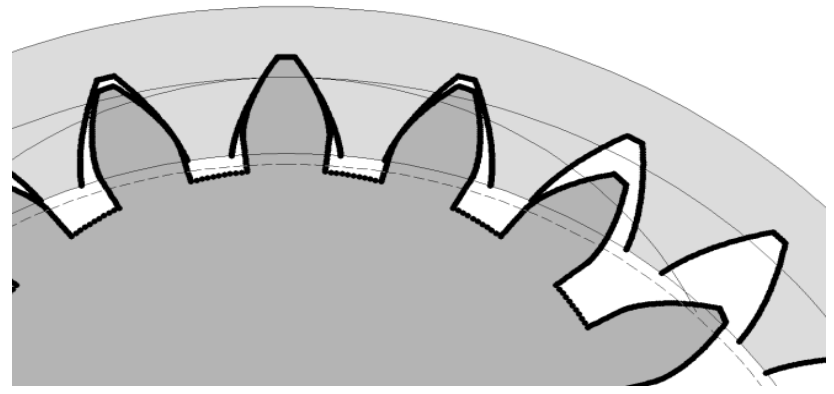

Şekil 9. Profil kaydırma ile girişimin önlenmesi (Avoiding trochoidal intereference with profile shifting)

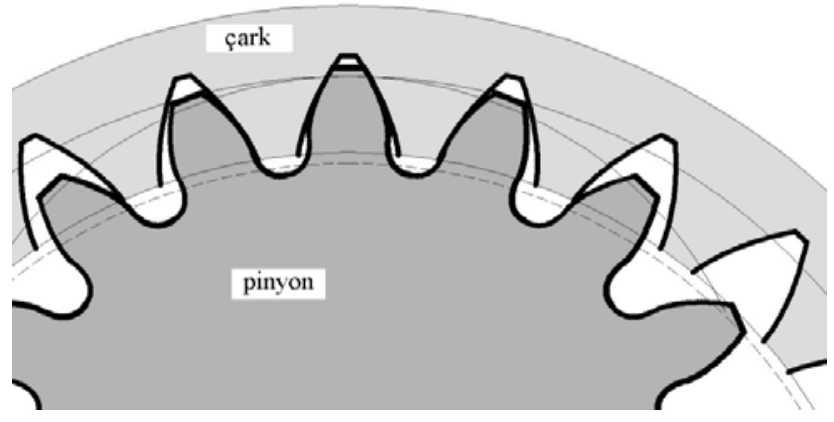

Şekil 10. Pinyon-çark mekanizması (Internal gear mechanism)

Takımın taslağa göre izafi konumlarının koordinatları verilen matematik modelin uygun düzenlenmesi ile elde edilebilir. Şekil 11'de sivri uçlu takımla imalat profil kaydırmasız ve profil kaydırma durumlar için ele alınmıştır. 
Modül $\mathrm{m}=3 \mathrm{~mm}$, takım diş sayısı $\mathrm{T}_{\mathrm{c}}=20$, çark diş sayısı $\mathrm{T}_{\mathrm{g}}=12$, kavrama açısı $\alpha=20^{\circ}$ alınmıştır. Bu durumda Şekil $11 \mathrm{a}$ 'da görüldüğü üzere alttan kesme söz konusudur. Çarka $\mathrm{x}_{2}=0,5$ profil kaydırma faktörü uygulanarak alttan kesmenin önlenmesi ve daha iyi bir diş formu elde edilmesi Şekil $11 b$ 'de görselleştirilmiştir. İmal edilen çarkın diş başı yarıçap1 profil kaydırmasız durumda $r_{a}=21 \mathrm{~mm}$ ve profil kaydırmalı durumda $r_{a}=22,5 \mathrm{~mm}$ olarak hesaplanmıştır.

\section{SONUÇLAR VE TARTIȘMALAR (RESULTS AND DISCUSSIONS)}

Pinyon-tipi takım dişli çark endüstrisinde yaygın olarak kullanılmaktadır. Literatürde iç ve dış dişlerin pinyon-tipi takımla matematik modellenmesi ve simülasyonu ile ilgili çalışmalar mevcuttur. Alt kesilmeyi önlemek, mekanizmayı istenen eksenler arası mesafeye yerleştirmek ve dişlerin mukavemeti artırmak için birçok uygulamada profil kaydırmalı dişliler kullanılmaktadır. Eksenler arası mesafenin değiştiği profil kaydırmalı mekanizmalar Vmekanizmaları olarak adlandırılır. Mesafe değişimi dişlilere verilen kaydırma miktarlarının toplamı kadar olabilmektedir. Ancak bu şekilde yerleştirmede dişli çiftinin yanakları arasında her iki yönde yanboşluk olarak adlandırılan boşluk bulunur. Şekil 4'de yan boşluklu durum görselleştirilmiştir. Buda gürültülü çalışmaya ve ilave zorlanmalara neden olmaktadır. Bunu önlemek için genişletilmiş eksenler arası mesafe profil kaydırmadan kaynaklanan yan boşluğu sıfirlayacak ölçüde daraltılmaktadır. Neticede yan boşluksuz çalışan profil kaydırmalı mekanizmalar elde edilir. Literatürde pinyontipi takımla profil kaydırmalı imalatı modelleyen çalışmalar ise yan boşluklu durumu incelemişlerdir $[6,16]$. Gerek iç ve gerekse dış dişlilerin imalatında takımla imal edilen taslak diş sayıları arasında bazı sınırlamalar bulunmaktadır. Dış dişlerin imalatında eş çalışan dişlerdeki girişim sınırına benzer şekilde sınır diş sayısı bulunmaktadır. Girişim ve alttan kesme istenmeyen bir husustur. Mabie ve Reinholtz sivri uçlu takım için sınır diş sayısı ifadesini sunmuştur. Chang ve Tsay evolvent profilli düz dişli pinyon-tipi sivri uçlu takımla eliptik dişlilerin imalatında sınır diş sayısını veren ifadeyi elde etmişlerdir. İç dişli çarklarda ise farklı girişim tipleri vardır. En temel girişim tipi çarkın temel dairesinin diş başı dairesinin üzerinde kalmasıdır. Burada diș yüksekliğinin azaltılması veya profil kaydırma yoluna gidilir. Aynı dizayn parametreleri için sivri takımla ve yuvarlatılmış uçlu takımla dış dişli imalatında sınır diş sayıları karşılaştırılması Bölüm 4.1'de verilen ifadelerle yapılabilir. Takım diş sayısı 20, modül $3 \mathrm{~mm}$, kavrama açısı $20^{\circ}$, taksimat yarıçapı $30 \mathrm{~mm}$ ve dişbaşı yarıçapı $33,75 \mathrm{~mm}$ için sivri uçlu takımda $\mathrm{f}=1,25$ ve sınır diş sayısı 14 numaralı eşitlikten $\mathrm{T}_{\text {gmin }}=17$ olarak hesaplanır. Yuvarlatılmış uçlu takımda $\rho=0,25 \times \mathrm{m}$ için $\mathrm{f}=1,132$ ve $\mathrm{T}_{\text {gmin }}=15$ olarak hesaplanır. Yuvarlatılmış uçlu takımda aynı dizayn parametreleri için daha küçük sayıda dişli alt kesilmesiz açılabilmektedir. Takım ucunun yuvarlatılması imal edilen dış dişlinin sınır diş sayısına etki etmektedir. Literatürde sivri uçlu takım için verilen evolvent sınır yüksekliğin yuvarlak uçlu takımda nasıl hesaplanacağı dördüncü bölümde verilmektedir. Yuvarlatılmış uçlu takımda maksimum evolvent bölge yarıçapının takım diş başı yarıçapı, temel dairesi yarıçapı ve uç yuvarlatma yarıçapına bağlı olarak veren ifade elde edilmiştir. Ayrıca evolvent açısının maksimum değerinin hesaplanması ve takım uç yarıçapını maksimum evolvent yarıçapına etkisi bir sayısal uygulama aşağıda verilmiştir.

Açık olarak sivri uçlu takım durumunda evolvent bölge takım dişbaşı dairesinde sonlanmaktadır. Takım diş sayısı $\mathrm{T}_{\mathrm{c}}=20$ ve modül $\mathrm{m}=3 \mathrm{~mm}$ için sivri uçlu takım durumunda maksimum evolvent açısı $\xi_{\mathrm{m}}=0,658245$ ve maksimum evolvent yarıçapı $\mathrm{R}_{\mathrm{A}}=33,75 \mathrm{~mm}$ olarak hesaplanır. Köşelerinden yuvarlatılmış uç durumunda maksimum evolvent yarıçapı takım dişbaşı yarıçapından farklıdır ve $\rho=0,25 \times \mathrm{m}$ için $\xi_{\mathrm{m}}=0,635124$ ve maksimum evolvent yarıçapı $\mathrm{R}_{\mathrm{A}}=33,39602 \mathrm{~mm}$ olarak hesaplanır. Takım standart dişbaşı yarıçapı $R_{B}=33,75 \mathrm{~mm}$ dir. Profil kaydırmanın alt sınırını alttan kesme, üst sınırını ise sivri tepe tayin eder. Isıl işlem durumuna göre diş başı kalınlığını belirli bir değerin altında olması istenmez. Yan boşluksuz çalışmada mekanizmada baş boşluğununda (clearance)
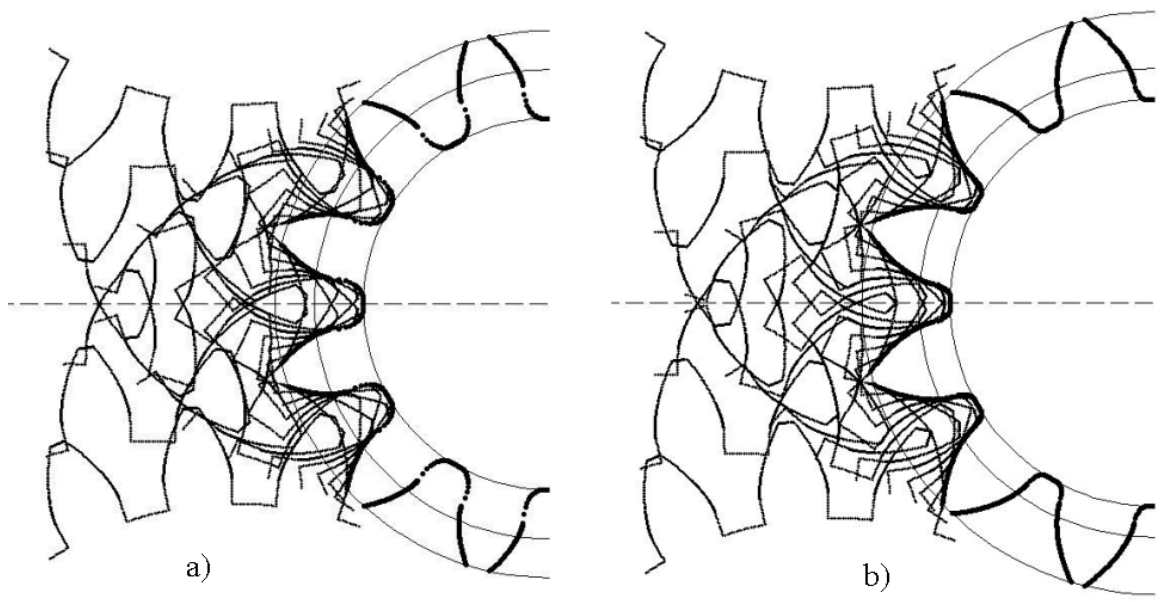

Şekil 11. Takım izafi konumlarının görselleştirilmesi (Relative positions of generating cutter) 
sağlanması gerekmektedir. Eş çalışan çarklardan birini diş başının diğerinin diş dibine temas etmemesi gerekir ve boşluk için sınırlayıcı değerler vardır. Bu nedenle kaydırmalı diş başları uygun miktarda torna edilir. Bu çalışmada iç ve diş dişli çarklarda yan boşluksuz profil kaydırma durumu incelenmiştir. Çeşitli dizayn parametrelerinin imal edilen diş geometrisi üzerindeki etkilerin incelemek için uygun bir programlama yaklaşımı ile matematik model bilgisayar ortamına aktarılmış ve sonuçlar görselleştirilmiştir. Şekil 6'da profil kaydırmanın üst sınırı olan sivri tepe durumu gösterilmiştir. Burada istenen baş boşluğunu sağlamak ve sivri tepeyi önlemek için baş kısaltması yapılmıştır. Şekil 8'deki iç dişli uygulamasında ise imal edilen dişli çark evolvent girişim sınırı altında olduğu için önlemek üzere standart değeri altında baş yüksekliği alınmıştır. Fakat diş sayıları arasındaki fark 9'dan küçük olduğu için takım uç girişimi önlenememiştir. Şekil 9'da standart referans profil ve profil kaydırma uygulanarak her iki girişimin önlenmesi görselleştirilmiştir. Şekil 11'de sivri uçlu takımla dış dişli imalatın takımın izafi konumları görselleştirilmiştir. Sınır diş sayısının altında bir dişli ele alınmıştır. Standart yerleştirmede imal edilen dişlide alt kesilme görülmektedir. Profil kaydırmalı durumda ise diş kökü formu iyileşmiştir. Takımın izafi konumlarının görselleştirilmesinden hareketle kaldırılan talaş miktarı tayin edilebilir ve takım ömrü ile ilgili analizler yapılabilir.

\section{SONUÇLAR (CONCLUSIONS)}

$\mathrm{Bu}$ çalışmanın amacı, incelemeler, yapılan çalışmalar ve elde edilen sonuçlar aşağıda özetlenmiştir. Çalışmanın amacı pinyon takımla imal edilen dişli çark mekanizmalarının matematik modellenmesi, bilgisayar simülasyonu ve çeşitli tasarım parametrelerinin imal edilen dişlilerdeki etkilerini incelemektir. İmalatta sınırlayıcı faktörler nedeniyle uygulanması gereken profil kaydırmada dikkat edilmesi gerekenler ele alınmıştır. Pinyon-tip takımla dişli imalatında takım ve imal edilen diş sayıları keyfi seçilememektedir. Girişim ve alttan kesme en önemli sınırlayıcı faktörlerdir. Dış dişli imalatında eş çalışan dişlilerdeki girişim ifadesinden hareketle sivri uçlu takım için alt kesilmesiz sınır diş sayısı elde edilir. Bu çalışmada bu ifade yuvarlatılmış uçlu takım için modifiye edilmiştir. Takım geometrisinde hareketle elde edilen ifade dördüncü bölümde sunulmuştur. İç dişli çarklarda farklı girişim tipleri olmakla birlikte evolvent girişimde imal edilecek dişlinin baş yüksekliğinin azaltması, uç girişimde ise takım-taslak diş sayıları arasındaki farkın 9 dan büyük olması profil kaydırma gerektirmeyen bir önleyici çözüm olabilir. Profil kaydırma gerek kremayer-tipi ve gerekse pinyon tipi takımla imalatta girişim ve alttan kesmeyi önlemede en çok kullanılan yöntemdir. Uygulanan yöne göre imal edilen dişin sivrileşmesi veya alttan kesilmesi sınırlayıc faktörlerdir. Eksenler arası mesafenin değiştiği profil kaydırmalı mekanizmalar (V-Mekanizmaları) boşluklu ve boşluksuz olarak ikiye ayrılır. Boşluklu durumda temas eden diş yanakları arasında mekanizmada gürültülü çalışmaya neden olan yan boşluk söz konusudur. Pratikte 60 mekanizmalar eksen mesafesi bu boşluğu giderecek şekilde daraltılmış olan boşluksuz V- mekanizmalarıdır. Boşluksuz mekanizmalarda kaydırmalı dişlerin uçlarının kısaltılması gerekebilir. Literatürde benzer çalışmalarda profil kaydırma uygulamasında yan boşluklu V-mekanizmaların ele alındığ görülmüştür $[6,16]$. Bu çalışmada ise literatürdeki modelden hareketle takım-taslak dönüşüm matrisinde eş çalışma taksimat (yuvarlanma) daireleri yarıçapları yan boşluksuz V-mekanizmaları için uygulanmaktadır. Bölüm 4'de çeşitli parametrelerin ve büyüklüklerin hesabı detaylı olarak verilmektedir. Örnek olarak yuvarlatılmış uçlu takımla dış dişli imalatında sınır diş sayısı için ifadenin nasıl elde edileceği ayrıntılı gösterilmiştir.

"Bilgisayar Uygulamaları" bölümünde profil kaydırmanın etkileri inceleyen çeşitli örnekler verilmiştir. Çeşitli senaryoların görselleştirildiği bu uygulamalar tasarım aşamasında imal edilecek diş geometrisi hakkında önbilgi vermekte ve muhtelif hatalar imalattan önce düzeltilebilmektedir. İç dişli çarklarda girişim durumu ve nasıl önlenebileceği de görselleştirilmiştir. Alt kesilmenin daha ciddi görüldüğü sivri uçlu takımla dış dişli imalatında profil kaydırmanın etkisi takımın izafi pozisyonların görselleştirildiği bir uygulama ile ele alınmıştır. İzafi konumlarının görselleştirmesi ileriki çalışmalarda talaş geometrisinin tayininde ve buna bağlı olarak takım ömrünün analizinde kullanılabilir. Sunulan bu çalışma helisel dişli çarklara ve iç düz dişli beveloid çarklara genişletebilir. Ayrıca çeşitli imalat ve fonksiyonel modifikasyonlar uygun düzenlemeler ile adapte edilebilir.

\section{KAYNAKLAR (REFERENCES)}

1. Çakmak S., Dişli Çarklar: Geometri-MukavemetTeknoloji, İstanbul, 1980.

2. Jelaska D.T., Gears and Gear Drives, John Wiley \& Sons, West Sussex, UK, 2012.

3. Güllü E., Yilmaz T.G., Investigation of surface pressure and elastic deformation on external and internal spur gear, Journal of the Faculty of Engineering and Architecture of Gazi University, 32 (2), 585-591, 2017.

4. Litvin F.L., Gear Geometry and Applied Theory, Prentice Hall, New Jersey, USA, 1994.

5. Chang S.L., Tsay C.B., Computerized tooth profile generation and undercut analysis of noncircular gears manufactured with shaper cutters, Journal of Mechanical Design, 120 (1), 92-99, 1998.

6. Tsay C.B., LiuW.Y., Chen Y.C., Spur gear generation by shaper cutters, Journal of Materials Processing Technology, 104 (3), 271-279, 2000.

7. Fetvaci C., Computer Simulation of Involute Tooth Generation, Mechanical Engineering, InTech, Rijeka, Croatia, 503-526, 2012.

8. Fetvaci M.C., Determination of effective involute parameter limit in generation simulation of gears manufactured by pinion-type cutters, Journal of the Faculty of Engineering and Architecture of Gazi University, 31 (2), 449-445, 2016. 
9. Liu C.C., Chen Y.C., Peng Y.L. Contact Pattern Simulation and Stress Analysis of Intersected Concave Conical Involute Gear Pairs Generated by Shaper Cutters, 14th IFToMM World Congress, Taiwan, 259264, 25-30 Ekim, 2015.

10. Chen Q., Song C., Zhu C., Du X., Ni G., Manufacturing and contact characteristics analysis of internal straight beveloid gear pair, Mechanism and Machine Theory, 114, 60-73, 2017.

11. Nemcek M., Tip Rounding of a Spur-Gear Pinion-Type Cutter, Modern Methods of Construction Design : Proceedings of ICMD2013, Springer International Publishing, Switzerland, 155-160, 2014.

12. Zhou H., Song W., Theoretical flowrate characteristics of the conjugated involute internal gear pump, Imeche Journal of Mechanical Engineering, 227 (4), 730-743, 2013.
13. Mabie H.H. ve Reinholtz C.F., Mechanisms and Dynamics of Machinery, John Wiley \& Sons, Singapore, 1987.

14. Litvin F.L., Hsiao C.L., Wang J.C., Zhou, X., Computerized simulation of generation of internal involute gears and their assembly, Journal of Mechanical Design, 116 (3), 683-689, 1994.

15. Svahn M., The undercut criterion of pinion shaper cutters: and an improvement by modifying the basic rack profile, Journal of Manufacturing Science and Engineering, 138 (1), 011011, 2016.

16. Fetvacı C., Tashihli düz dişlilerin pinyon takımla imalatının bilgisayar simülasyonu, Mühendis ve Makina, 53 (625), 79-86, 2012.

17. Merritt H.E., Gears, Sir Isaac Pitman \& Sons, London, UK, 1962. 
